\title{
Natural illite as an Efficient Adsorbent for Thorium Removal
}

\author{
Hongxia Zhang ${ }^{1,2 *}$, Xiaoyun Wang ${ }^{1}$, Yunjie Jiang ${ }^{1}$, Tianshe Tan ${ }^{1}$, Kaiwen Shen $^{3}$, \\ Wangsuo $\mathrm{Wu}^{1,2}$ \\ ${ }^{1}$ Radiochemistry Laboratory, School of Nuclear Science and Technology, Lanzhou University, \\ Lanzhou, China; \\ ${ }^{2}$ Key Laboratory of Special Function Materials and Structure Design, Ministry of Education, Lanzhou \\ University, Lanzhou, China. \\ ${ }^{3}$ State Nuclear Power Demonstration Plant Company Limited, Weihai, China.
}

\begin{abstract}
In this paper, the natural illite is used as low-cost sorbent for investigating the sorption of Th(IV). The sorbent is characterized by titration, $N_{2}$-BET, FTIR, XRD, SEM/EDS and XPS. The sorption behavior of $T h(I V)$ on the sorbent is investigated by batch method. The kinetics of Th(IV) adsorption process on the sorbent is fitted well by the pseudo-second order rate equation. The sorption capacity of Th(IV) is increased with the solid-to-liquid ratio increasing. The sorption of Th(IV) is strongly dependent on $\mathrm{pH}(\mathrm{pH}<5)$ and ionic strength. The negative effects on sorption of cations shown from strong to weak is: $\mathrm{Mg}\left(\mathrm{NO}_{3}\right)_{2}>\mathrm{KNO}_{3}>\mathrm{NaNO}_{3}$. The influence of the anions are: $\mathrm{PO}_{4}{ }^{3-}$ obviously promoted $\mathrm{Th}(\mathrm{IV})$ sorption, while the existence of $\mathrm{SO}_{4}{ }^{2-}$ inhibited Th(IV) adsorption. Gibbs free energy $\left(\Delta G^{0}\right)$, Enthalpy $\left(\Delta H^{0}\right)$ and entropy $\left(\Delta S^{0}\right)$ and are calculated from the temperature-dependent sorption data and the results indicate that the sorption of Th(IV) on natural illite was a spontaneous process. Isotherms of Th(IV) adsorption to natural illite could be described well by Langmuir model. Through the desorption experiments, the adsorption process on natural illite was reversible reaction. The sorption mechnism of Th(IV) on natural illite is ion exchange reaction with its potassium ions that are trapped in its interlayer spaces; as well as outer sphere complexes formation $(\mathrm{pH}<5)$ and inner sphere complexes $(\mathrm{pH}>5)$ through $\equiv \mathrm{Si}-\mathrm{O}$ - and $\equiv \mathrm{Al}-\mathrm{O}$ - groups are located at the edges.
\end{abstract}

Keywords: natrual illite; Th(IV); sorption; kinetics; isotherm.

\section{INTRODUCTION}

With the development of nuclear energy, the nuclear critical safety problem becomes more and more significant. In particular, some long-lived radionuclides have attracted people ( $\mathrm{Yu}$ et aL, 2015; Kitamura and Kirishima, 2015). Radionuclides with high mobility in contaminated water will transfer into soil and plant materials. The radionuclides will enter the food chain, which will potentially produce serious damage to human beings(Wen et aL, 2014). Among these nuclear waste and fission products, one of the elements that cause people to pay attention to is thorium. Thorium, which is a potential nuclear fuel and fertile in mining tailings and wastewater from disposal plants, is one of the most significant radioactive contaminations in environmental medium(Pan et $a L, 2011$; Xu et aL, 2016). Additionally, It is only stable at its valence +4 in solution, and is usually selected as a chemical analogue for other tetravalent actinides(Choppin, 1999). Since that is not biodegradable and tends to accumulate in living organisms, causing various diseases and disorders, the separation and enrichment of Th(IV) from aqueous solutions are crucial in protecting environment and reutilizing thorium as a resource (Pan et aL, 2011; Xu et aL, 2016). Th(IV) on all kinds of clay minerals and oxides are most important for determining the mobility and bioavailability of $\mathrm{Th}(\mathrm{IV})$ in the natural environment ( Chen and Wang, 2007; Chen et aL, 2007; Tan et aL, 2007; Xu et aL, 2007). In recent decade years, the sorption of Th(IV) on all kinds of minerals as a function of $\mathrm{pH}$, ionic strength, temperature was studied extensively (Xu et aL, 2007; Fan et aL, 2008; Pan et aL, 2011; Hu and Tan, 2012; Zhang et $a L$, 2015). Many mechanisms have been postulated for Th(IV) and other actinides of sorption, such as

Corresponding author: E-mail address: hxzhang@lzu.edu.cn 
surface complexation, chemi-complexation, chemisorption, cation exchange, surface precipitation, colloid formation at surface and diffusion into the particle micropores (Jakobsson,1999; Reiller et aL, 2005; Wang et aL, 2005a; Wang et aL, 2005b; Wang et aL, 2005c) .

Illite is 2:1 layer type clays: its structure consists of two tetrahedral sheets that sandwich an octahedral sheet, and non-expanding, aluminous, and contains nonexchangeable $\mathrm{K}$ as the major interlayer cation. The potassium balances a negative layer charge, generated by $\mathrm{Al}$ for Si substitution in the tetrahedral sheet and $\left(\mathrm{Mg}, \mathrm{Fe}^{2+}\right)$ for $\mathrm{Al}$ in the octahedral sheet. (Rieder et aL, 1998; Jan Środoń, 2005) Usually, illite is white, but when containing impurities it will become yellow, green, brown and other colors. Because illite has specific surface area, microcellular structure and high cation exchange capacity, it has a strong affinity for metallic pollutants in the environment. In the last decades, illite has been intensively investigated as an adsorbent in the removal of heavy metal ions from the solutions and heavy metal polluted soils in the natural environment, e.g. $\mathrm{Pb}(\mathrm{II}), \mathrm{Ni}(\mathrm{II}), \mathrm{Cu}(\mathrm{II}), \mathrm{Co}(\mathrm{II}), \mathrm{Eu}(\mathrm{II})$ and Zn(II) on illite (Echeverría et aL, 2005; Elzinga and Sparks, 2001; Bradbury and Baeyens, 2009; Turan et aL, 2011). There are large reserves of illite in China. Illite was first utilized in the 1940s, and has been mainly used as an absorbent, catalyst carrier, densifying agent, adhesive and food additive. In this paper, we will report the use of illite as a sorbent to study the sorption properties of $\mathrm{Th}(\mathrm{IV})$ at different experimental conditions.

In this work, natrual illite sample is characterized by a variety of detection means, such as powder Xray diffraction (XRD), Fourier transform infrared spectroscopy (FTIR) SEM/EDS, and XPS. The effect of contact time, temperature, solid-to-liquid ratio, $\mathrm{pH}$, ionic strength and foreign ions on $\mathrm{Th}(\mathrm{VI})$ sorption on natural illite is investigated using batch experiments. The sorption and desorption isotherms are measured. Study the sorption of $\mathrm{Th}(\mathrm{IV})$ at different temperatures and achieve the adsorption thermodynamic data (i.e., $\Delta \mathrm{G}^{0}, \Delta \mathrm{S}^{0}, \Delta \mathrm{H}^{0}$ ). Finally, discuss the sorption mechanisms of Th(IV) on natural illite.

\section{EXPERIMENTAL}

\subsection{Materials}

All chemicals and reagents used in this study are purchased as analytically pure and are used without any further purification. The natural micro-powder illite is supplied by Sushan Co. (Henan, China). It is treated with $5 \%$ hydrochloric acid for $24 \mathrm{~h}$, and then followed by washing with distilled water until no chloride is detectable in supernatant with $0.01 \mathrm{M} \mathrm{AgNO}_{3}$. After the sample dried, it is crushed to pass through 160-mesh screen and is stored in glass bottles for further use.

\subsection{Characterizations}

The content of elements and composite was obtained by XRF and XRD(X-Strata920, Oxford, Shanghai). The pore structure parameters relating to surface area, pore volume and average pore size were measured from $\mathrm{N}_{2}$ adsorption-desorption isotherms using a Micromeritics ASAP2020 instrument. Fourier transform infrared (FT-IR) spectroscopy was obtained in the wavenumber region of $4000-400 \mathrm{~cm}^{-1}$ with a Nicolet IS10 spectrometer using $\mathrm{KBr}$ pellets. The surface morphologies and the elemental composition of samples were observed using the S-4800 field-emission scanning electron microscope with energy dispersive spectrometer (SEM-EDS, Oxford, Shanghai). XPS (Thermo, US) was used to measure the elemental composition and chemical state of the surface elements on the natural illite. The surface charge and point of zero charge of natural illite was obtained by titrations (Zhang et aL, 2016).

\subsection{Batch Sorption Experiments}

The sorption behavior of Th(IV) onto the sorbent is investigated by using batch technique in polyethylene centrifuge tubes sealed with screw-cap under ambient conditions. A stock solution of $\mathrm{Th}\left(\mathrm{NO}_{3}\right)_{4}$ is prepared by dissolving $\mathrm{Th}\left(\mathrm{NO}_{3}\right)_{4} \cdot 6 \mathrm{H}_{2} \mathrm{O}$ in Milli-Q water. The stock solutions of $\mathrm{NaNO}_{3}, \mathrm{Th}(\mathrm{IV})$, and natural illite are added in the polyethylene centrifuge test tubes to achieve the desired concentration of different components. The $\mathrm{pH}$ values of the solution are adjusted by adding negligible volume of $\mathrm{HNO}_{3}$ or $\mathrm{NaOH}$ solution. After the suspension is stirred, the solid and liquid phases are separated by centrifugation. The concentration of Th(IV) is analyzed by using a spectrophotometer at wavelength of $662 \mathrm{~nm}$ by using Th(IV) arsenazo(III) complex. The sorption of Th(IV) on the test tube walls is neglected ( Chen and Wang, 2007). 
For desorption experiments, after centrifugation at the end of sorption experiments, two-thirds of the supernatant is pipetted out and the equal volume of background electrolyte solution with same $\mathrm{pH}$ is added. Then the mixture is shaken and centrifuged at the same conditions as in sorption experiments.

The amount of adsorbed Th(IV) is determined from the difference between the Th(IV) concentration in the aqueous before and after the sorption. The percent sorption (\%) of Th(IV) from aqueous solution is calculated as follows:

$$
\operatorname{Sorption}(\%)=\frac{C_{0}-C_{e}}{C_{0}} \times 100 \%
$$

where $\mathrm{C}_{0}(\mathrm{~mol} / \mathrm{L})$ and $\mathrm{C}_{\mathrm{e}}(\mathrm{mol} / \mathrm{L})$ are the concentrations of $\mathrm{Th}(\mathrm{IV})$ at initial and equilibrium time, respectively. The sorption capacity $\left(\mathrm{q}_{\mathrm{e}}, \mathrm{mol} / \mathrm{g}\right)$ of $\mathrm{Th}(\mathrm{IV})$ on natrual illite is calculated using the following equation:

$$
q_{e}=\frac{\left(C_{0}-C_{e}\right) V}{m}
$$

where $\mathrm{V}$ is the volume of the solution $(\mathrm{L})$ and $\mathrm{m}$ is the mass of dry sorbent $(\mathrm{g})$.

Conformity between experimental data and kinetic models and thermodynamic model was determined by the correlation coefficient $\left(\mathrm{R}^{2}\right)$ and the residual root mean square errors (RMSE) which can be written as follows (Yari et aL, 2015):

$$
R M S E=\sqrt{\left(\frac{1}{n-1}\right) \sum_{i=1}^{n}\left(q_{i, \exp }-q_{i, \text { cal }}\right)^{2}}
$$

where $\mathrm{q}_{\mathrm{i}, \text { cal }}$ and $\mathrm{q}_{\mathrm{i}, \text { exp }}(\mathrm{mmol} / \mathrm{g}$ ) are the calculated and the experimental values of the sorption capacity, respectively, and $\mathrm{n}$ is the number of data points.

\section{RESUlTS AND DisCUSSION}

\subsection{Characterizations}

The $\mathrm{N}_{2}$-BET surface area and the chemical components of the micro-powder as analyzed by X-ray fluorescence diffraction is listed in Table.1.

Table 1. Chemical Composition of Natural Illite Sample (Wt\%, not including $\mathrm{C}$ and $\mathrm{H}_{2} \mathrm{O}$ )

\begin{tabular}{|l|l|}
\hline Components & Content (wt \%) \\
\hline $\mathrm{SiO}_{2}$ & 63.74 \\
\hline $\mathrm{Al}_{2} \mathrm{O}_{3}$ & 18.40 \\
\hline $\mathrm{K}_{2} \mathrm{O}$ & 7.92 \\
\hline $\mathrm{MgO}$ & 1.87 \\
\hline $\mathrm{Fe}_{2} \mathrm{O}_{3}$ & 7.36 \\
\hline $\mathrm{CaO}$ & 1.11 \\
\hline $\mathrm{Na}_{2} \mathrm{O}$ & 0.05 \\
\hline Parameter & test data \\
\hline BET surface area & $21.97 \mathrm{~m}^{2} / \mathrm{g}$ \\
\hline Pore volume & $0.047 \mathrm{ml} / \mathrm{g}$ \\
\hline pore size & $12.55 \mathrm{~nm}$ \\
\hline
\end{tabular}

The XRD characterization of the natural illite is shown in Fig.1. The XRD peak shows the sample consists mainly of illite, with associated quartz, goethite, calcite and montmorillonite. From Table 1 , the higher amount of Si in natural clay is due to the quartz content, which is supported by the XRD results (in Fig.1). The presence of relatively high concentration of Iron, $\mathrm{Mg}$ and $\mathrm{Ca}$ can be partly attributed to the presence of calcite and goethite, as indicated by XRD.

The FT-IR spectrum of natural illite sample is shown in Fig.2. According to the FTIR spectrum, the bands at $3,619 \mathrm{~cm}^{-1}$ and $3,629 \mathrm{~cm}^{-1}$ are assigned to the presence of the stretching vibration of Al-OH groups. The bend vibration of $\mathrm{H}_{2} \mathrm{O}$ is observed at $1,635 \mathrm{~cm}^{-1}$. The strong stretching vibration sorption band at $1,025 \mathrm{~cm}^{-1}$ corresponds to $\mathrm{Si}-\mathrm{O}$ (stretching vibration). The bands at 538 and $479 \mathrm{~cm}^{-1}$ are 
attributed to the bending vibration of $\mathrm{Si}-\mathrm{O}$ groups (Giustetto et $a L, 2005$; Boyd et aL, 1988; Xu and Boyd, 1994; Potgieter et $a L, 2006$ ). Besides, it is noted that the bands of $801 \mathrm{~cm}^{-1}$ and $830 \mathrm{~cm}^{-1}$ are matched with $\mathrm{Al} / \mathrm{Mg} / \mathrm{Fe}-\mathrm{OH}$ stretching, which only exists in natural illite FT-IR spectrum. It indicates that natural illite is mixed with some impurities that contain $\mathrm{Mg}$ or Fe element. This result is in conformity with Table.1.

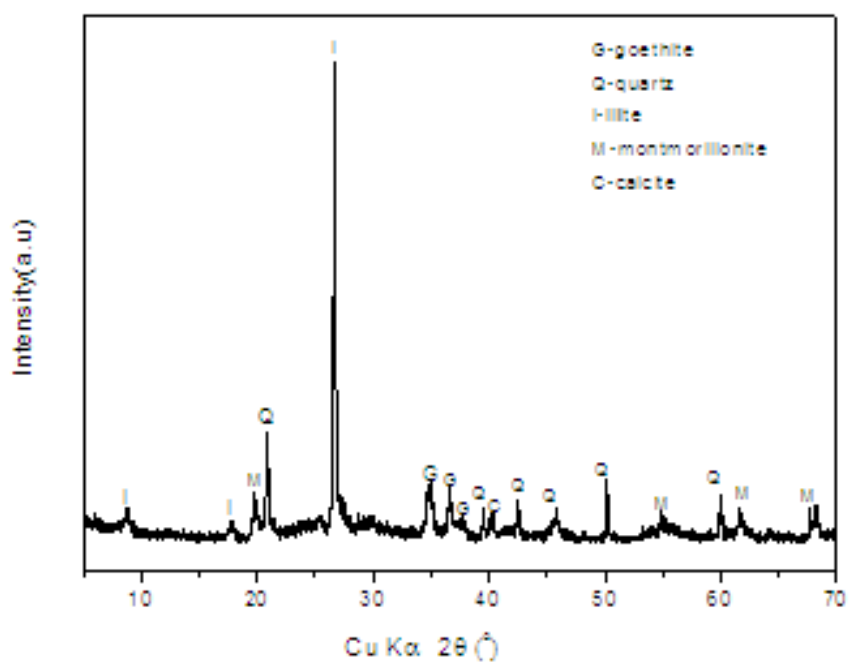

Fig. 1 The XRD spectra of the natural illite

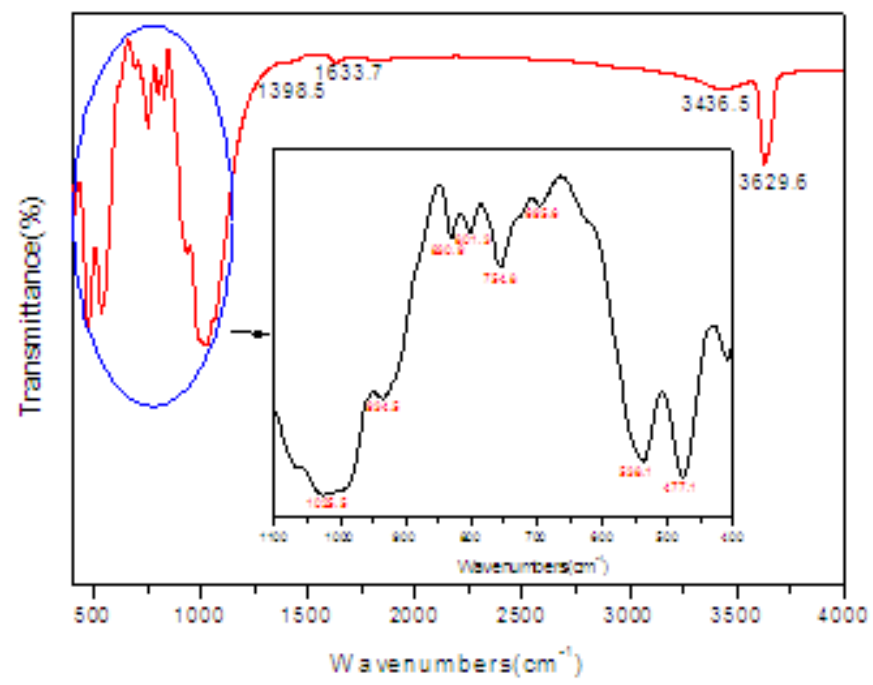

Fig 2. The FT-IR spectrum of natural illite
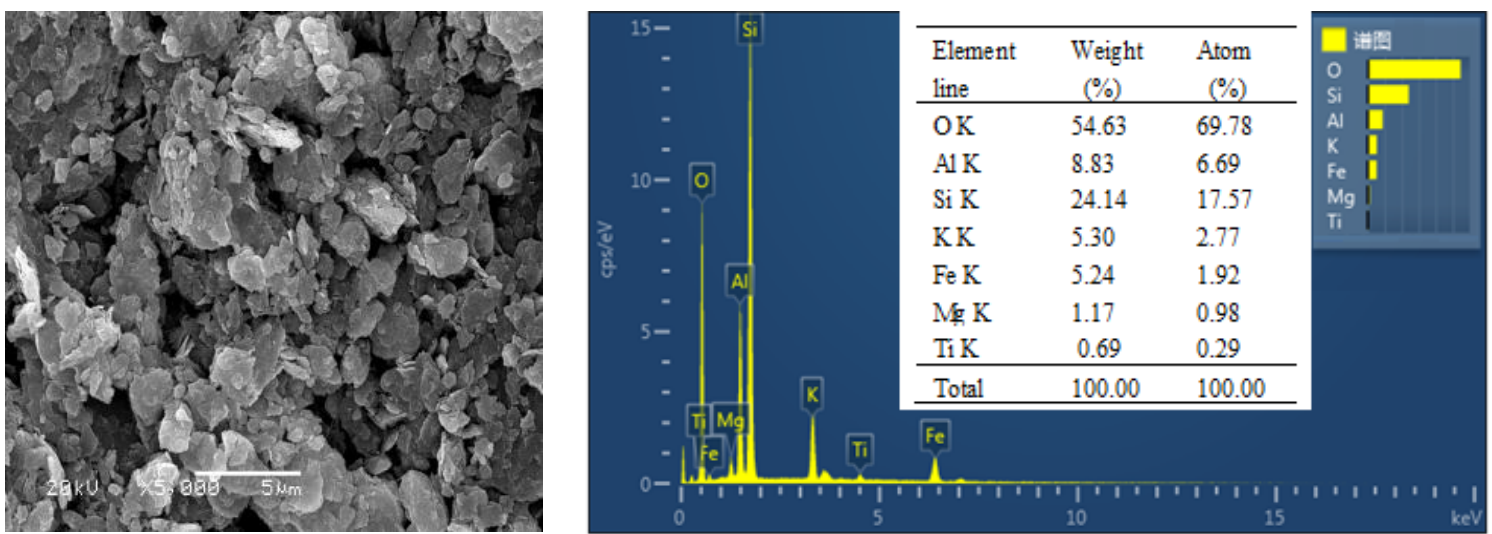

Fig 3. SEM/EDS of natural illite surface

Fig.3 shows the SEM image of natural illite. It can be seen they were flat, but the surface of natural illite is rougher because of impurities, which might influence the surface properties of sorbent. It may increase the specific surface area and provide more active sites. This conclusion is conformed to the results of $\mathrm{N}_{2}$-BET. EDS show the elements of natural illite surface, and the result is consistent with the result of X-ray fluorescence diffraction. 
Potentiometric titration can be employed to determine the nature of the surface charge and to calculate the density of active sites $\left(\mathrm{H}_{\mathrm{s}}\right)$ (liu et $a L, 1999$ ). The natural illite is characterized by potentiometric titration. The Gran function (G) is expressed as follows( Zhao et aL, 2007):

at acidic regime : $G_{a}=\left(V_{0}+V_{a}+V_{b}\right) \times 10^{-p H} \times 100$

at alkaline regime: $G_{b}=\left(V_{0}+V_{a}+V_{b}\right) \times 10^{-(13.8-p H)} \times 100$

where $G_{a}$ and $G_{b}$ are the Gran functions in the acidic and alkaline regimes of the titration, respectively. Meanwhile, $\mathrm{V}_{0}(\mathrm{~mL})$ denotes the initial solution volume, and $\mathrm{V}_{\mathrm{b}}(\mathrm{mL})$ corresponds to the volume of $\mathrm{NaOH}$ added at the different titration points. The two equivalence points, $\mathrm{V}_{\mathrm{eb} 1}$ and $\mathrm{V}_{\mathrm{eb} 2}$, which were obtained from linear regression analysis of the Gran plot's terminals, can be considered as the zero point and the end-point of the natural illites titration (seen Fig.4).
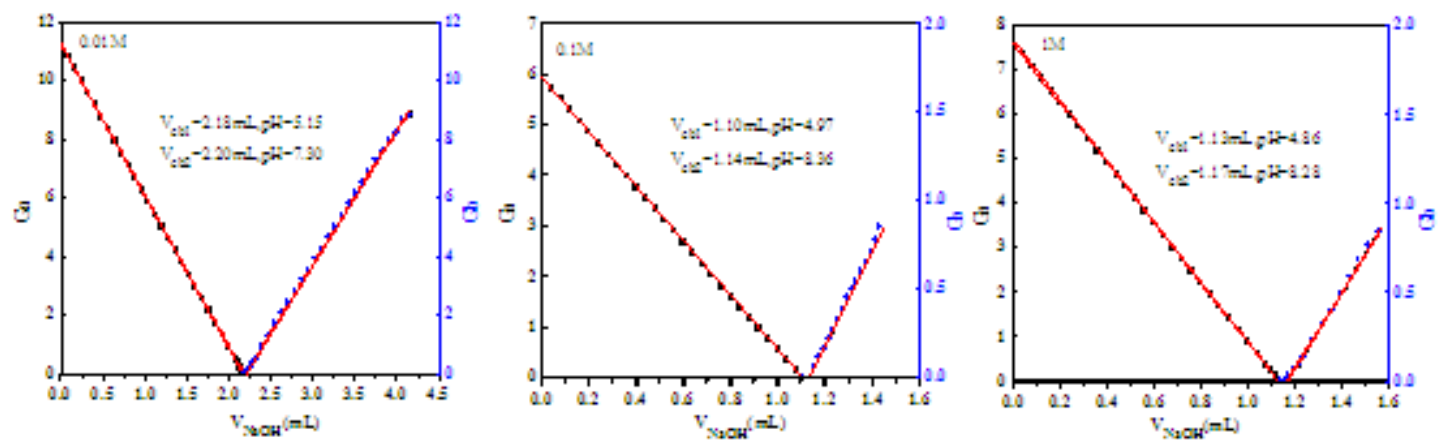

(a)
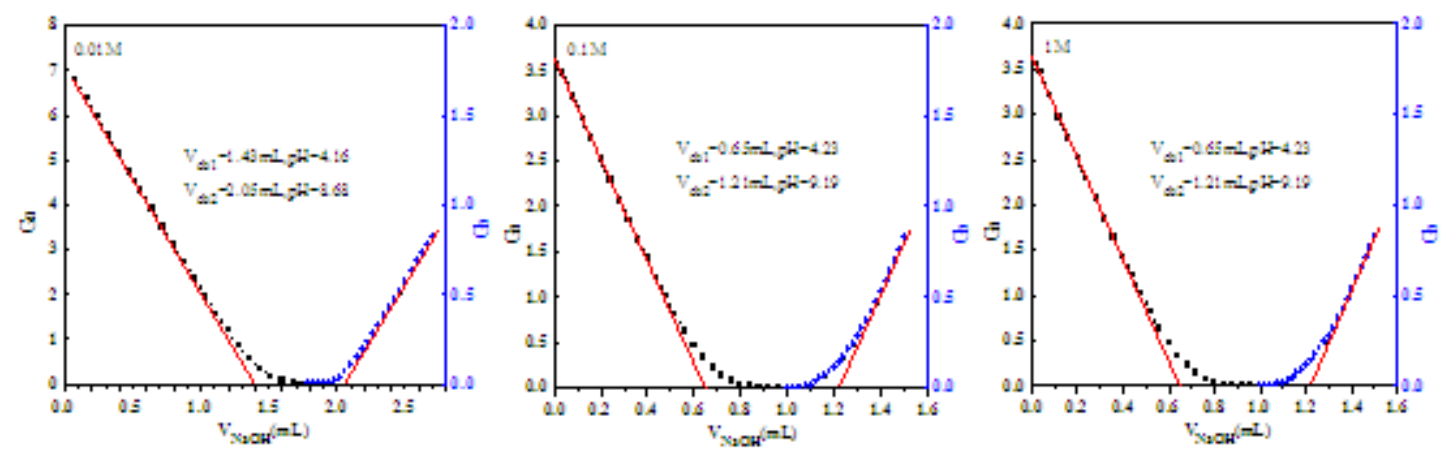

(b)

Fig 4. Gran plots of natural illite in 0.01, 0.1 and $1.0 \mathrm{M} \mathrm{NaNO}_{3}$ solutions at $20 \pm 1{ }^{\circ} \mathrm{C}$. (a) blank; (b)Natural illite.

The surface site density of natural illite is calculated from Eq. (6) (Wagner et $a L, 1979$ ):

$$
H_{s}=\frac{\left(V_{e b 2}-V_{e b 1}\right)_{\text {sample }} \times C_{b}-\left(V_{e b 2}-V_{e b 1}\right)_{b l a n k} \times C_{b}}{m}(\mathrm{~mol} / \mathrm{g})
$$

where $\mathrm{C}_{\mathrm{b}}(\mathrm{mol} / \mathrm{L})$ denotes the concentration of $\mathrm{NaOH}$. The $\mathrm{H}_{\mathrm{s}}$ values of illite in different ionic strength are listed in Table 2. It can be seen that the $\mathrm{H}_{\mathrm{s}}$ values of natural illite becomes smaller as the ionic strength increases from $0.01 \mathrm{M}$ to $1.0 \mathrm{M}$. This can predict the metal sorption on natural illite will significantly dependent on ionic strength. The TOTH refers to the concentration of protons consumed during the titration process. This value can be calculated from Eq. (7) (Wagner et aL, 1979)

$$
T O T H=\frac{-\left(V_{b}-V_{e b 1}\right) \times C_{b}}{V_{0}+V_{b}}(\mathrm{~mol} / \mathrm{L})
$$

Table 2. $H_{s}$ values of natural illite

\begin{tabular}{|c|c|c|c|}
\hline $\mathrm{C}_{\mathrm{NaNO} 3}(\mathrm{~mol} / \mathrm{L})$ & 0.01 & 0.1 & 1.0 \\
\hline $\mathrm{Hs}(\mathrm{mol} / \mathrm{g})$ & $1.20 \times 10^{-4}$ & $1.04 \times 10^{-4}$ & $8.99 \times 10^{-5}$ \\
\hline
\end{tabular}


Got from the value of TOTH as a function of $\mathrm{pH}$ (seen in Fig.5), the $\mathrm{pH}_{\mathrm{pzc}}$ (point of zero charge) is measured to be 4.2 for natural illite, and the result is consistent with the result of previous study(Zhang et aL, 2016). This indicates that the surface of natural illite is likely neutral or positively charged at $\mathrm{pH} \leq 4.2$ and negatively charged at $\mathrm{pH}>4.2$.

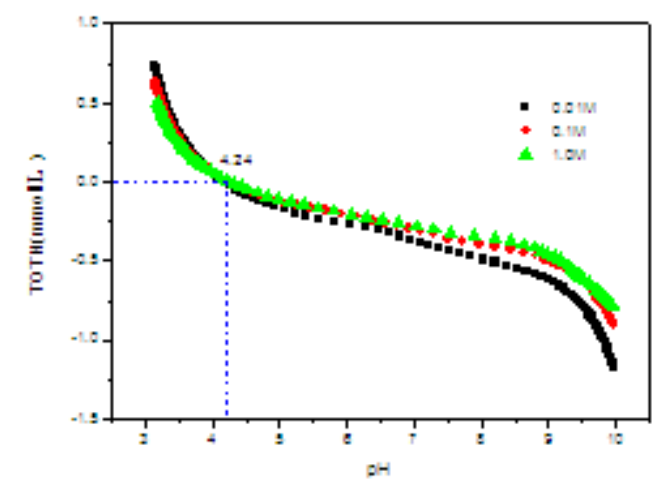

Fig 5. The surface site relative distribution calculated from titration curve of the natural illite, $T=25^{\circ} C, I=0.01$, $0.1,1.0 \mathrm{~mol} / \mathrm{L}, \mathrm{m} / \mathrm{V}=5.0(\mathrm{~g} / \mathrm{l})$

\subsection{Effect of solid-to-liquid $(\mathrm{m} / \mathrm{V})$ ratio}

The influence of solid-to-liquid ratio $(\mathrm{m} / \mathrm{V})$ on Th(IV) sorption to natural illite is shown in Fig.6. As expected, a higher $\mathrm{m} / \mathrm{V}$ is desirable for $\mathrm{Th}(\mathrm{IV})$ sorption on natural illite within the range $1-8 \mathrm{~g} / \mathrm{L}$. A probable explanation is that more sorption sites are available for Th(IV) sorption with increasing the content of natural illite (Asci et $a L, 2007$ ). However, the sorption of Th(IV) on natural illite arrived to the top quickly and kept stable with the $\mathrm{m} / \mathrm{V}$ increasing. This phenomenon can be explained because the natural illite has more sorption sites than of pure illite in the same $\mathrm{m} / \mathrm{V}$ and the sorbent concentration is more over the Th(IV) concentration(Zhang et $a L, 2016)$. When the sorbent concentration is high, the sorbent cannot disperse well and thus reduces the effective sites of functional groups at illite surface and results in the sorption and complexation ability of natural illite decreases as the $\mathrm{m} / \mathrm{V}$ increasing (Xu et $a L, 2006$ ). The $\mathrm{m} / \mathrm{V}$ dependence is actually consistent with the prediction of the pseudo-second-order model in the kinetic estimation above. The distribution coefficient $\left(\mathrm{K}_{\mathrm{d}}, \mathrm{L} / \mathrm{g}\right)$ is also plotted as a function of $\mathrm{m} / \mathrm{V}$ in Fig.6. $\mathrm{K}_{\mathrm{d}}$ can be calculated from the concentration of $\mathrm{Th}(\mathrm{IV})$ in suspension $\left(\mathrm{C}_{0}\right)$ and in the supernatant liquid $\left(\mathrm{C}_{\mathrm{e}}\right)$ according to Eq. (8) $(\mathrm{Xu}$ et aL, 2006):

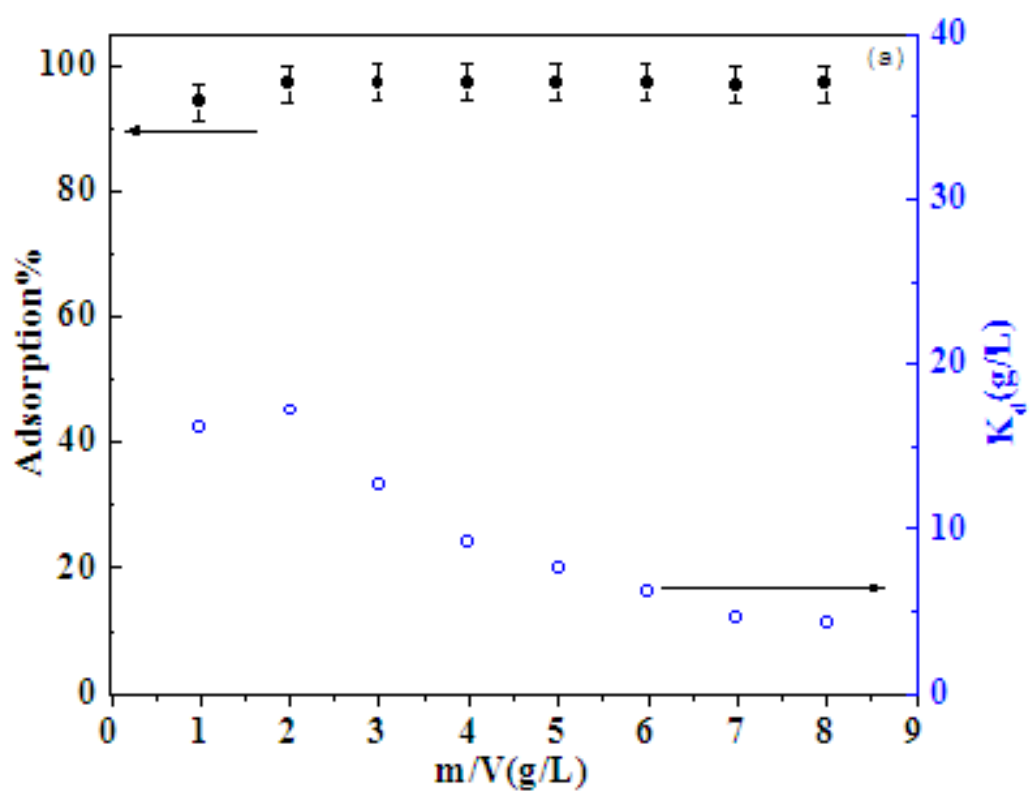




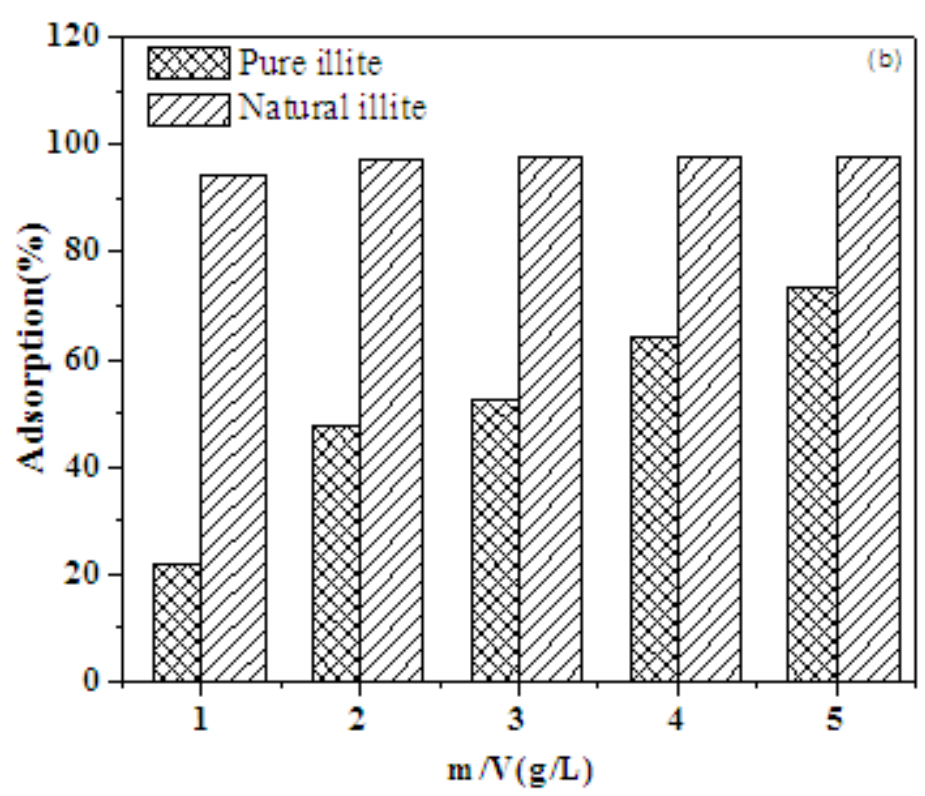

Fig. 6 (a)The effect of $m / V$ on the adsorption of Th(IV) on natural illite (b)comparison of percentage of Th(IV) adsorbed on pure illite and natural illite

$p H=3.50 \pm 0.03, t=20 \mathrm{~h}, I=0.01 \mathrm{M} \mathrm{NaNO}_{3}, \mathrm{~T}=25 \pm 2^{\circ} \mathrm{C}, C_{T h(I V)}=2.0 \times 10^{-4} \mathrm{~mol} / \mathrm{L}$

$$
K_{d}=\frac{\left(C_{0}-C_{e q}\right) V}{m C_{e q}}
$$

where $\mathrm{V}$ is the volume of the suspension $(\mathrm{L})$ and $\mathrm{m}$ is the mass of the natural illite $(\mathrm{g})$. It should be noted that the value of $K_{d}$ is weakly dependent on the ratio of $\mathrm{m} / \mathrm{V}$, which is consistent with the physicochemical properties of the $K_{d}$ value. However, the value of $K_{d}$ of natural illite is getting smaller gently, which has the same reason as the phenomenon of the sorption rate of natural illite.

\subsection{Sorption Kinetics}

The time-dependent experiment was conducted to evaluate the effect of contact time and understand the adsorption mechanism, especially the kinetic aspect. As can be seen from Fig.7(a), the sorption of Th(IV) was quick. The sorption achieved equilibration in less than 5h, and then the sorption of Th(IV) from solution to natural illite maintained level off with increasing contact time. In the following experiments, more than $20 \mathrm{~h}$ was selected to make the sorption equilibration of $\mathrm{Th}(\mathrm{IV})$ on natural illite.

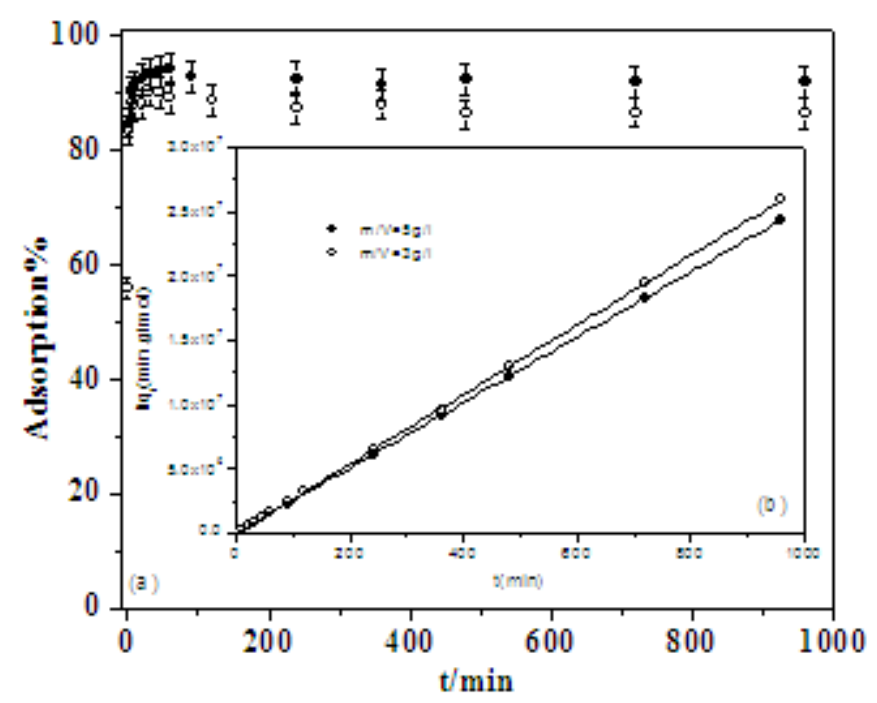

Fig 7. (a) Kinetics of Th(IV) sorption onto the natural illite at $0.01 \mathrm{M}$ ionic strength, $p H=3.50 \pm 0.03, T=25 \pm 2{ }^{\circ} \mathrm{C}, C_{T h(I V)}=2.0 \times 10^{-4} \mathrm{~mol} / \mathrm{L}, \mathrm{pH}=4$,

(b) Pseudo-second-order kinetics of $T h(I V)$ adsorption onto the natural illite 
A suitable kinetics model can provide useful information in determining the underlying mechanism during the sorption process. To analyze the adsorption rate and mechanism of Th(IV) on illite, a pseudo-second-order rate equation was applied to simulate the kinetic sorption (Ho Y.S., 2006):

$$
\frac{t}{q_{t}}=\frac{1}{k q_{e}{ }^{2}}+\frac{t}{q_{e}}
$$

where $k\left(\mathrm{gmol}^{-1} \mathrm{~min}^{-1}\right)$ is the pseudo-second-order rate constant of adsorption, $q_{t}\left(\mathrm{gmol}^{-1}\right)$ is the amount of $\mathrm{Th}(\mathrm{IV})$ adsorbed on illites at time $t(\mathrm{~h})$, and $q_{e}\left(\mathrm{gmol}^{-1}\right)$ is the equilibrium adsorption capacity. Linear plot feature of $t / q t$ vs. $t$ is shown in Fig.7(b). The $k$ and $q_{e}$ values at different $\mathrm{m} / \mathrm{V}$ are calculated from the slope and intercept, respectively, and the results list in Table 3. A smaller RMSE and higher $\mathrm{R}^{2}$ values indicated that the kinetic adsorption could be described by a pseudo-secondorder rate equation well. The process of the Th(IV) sorption on illites may be chemisorption involving valency forces through sharing or exchange of electrons between sorbent and sorbate (Ho and Makay, 2000). A smaller RMSE and higher $\mathrm{R}^{2}$ values indicate a better curve fitting (Keshtkar and Abbasizadeh, 2016; Yari et $a L, 2015 b)$.

Table 3. The values of parameters obtained from the pseudo-second-order rate equations

\begin{tabular}{|c|c|c|c|c|c|}
\hline Pseudo-second-order model & $\begin{array}{l}\mathrm{m} / \mathrm{V} \\
(\mathrm{g} / \mathrm{L})\end{array}$ & $\begin{array}{c}\mathrm{K} \\
(\mathrm{g} /(\mathrm{mol} \cdot \mathrm{min}))\end{array}$ & $\begin{array}{c}\mathrm{q}_{\mathrm{e}} \\
(\mathrm{mmol} / \mathrm{g})\end{array}$ & $\mathrm{R}^{2}$ & RMSE \\
\hline \multirow{2}{*}{$\frac{t}{q_{t}}=\frac{1}{k q_{e}{ }^{2}}+\frac{t}{q_{e}}$} & 5 & $2.85 \times 10^{4}$ & 0.0393 & 0.9999 & 0.0004 \\
\cline { 2 - 6 } & 3 & $1.99 \times 10^{4}$ & 0.0377 & 0.9998 & 0.0007 \\
\hline
\end{tabular}

\subsection{Effects of pH and Ionic Strength}

Removal percent of Th(IV) from solution to natural illite as a function of $\mathrm{pH}$ values in 0.1 and $1 \mathrm{M}$ $\mathrm{NaNO}_{3}$ solutions is shown in Fig.8(a). Sorption of Th(IV) occurs at low $\mathrm{pH}$ value and a sharp increase in sorption from $25 \%$ to $90 \%$ of the added Th(IV) concentration occurs over the $\mathrm{pH}$ range from 1 to 4 . Then the sorption of Th(IV) on illite remains level with increasing $\mathrm{pH}$ value. The strongly $\mathrm{pH}$ dependent sorption of Th(IV) on natural illite suggests that surface complexation contributes mainly to the sorption of Th(IV) on natural illite.(Wu et aL, 2007; Baeyens and Bradbury,1997)

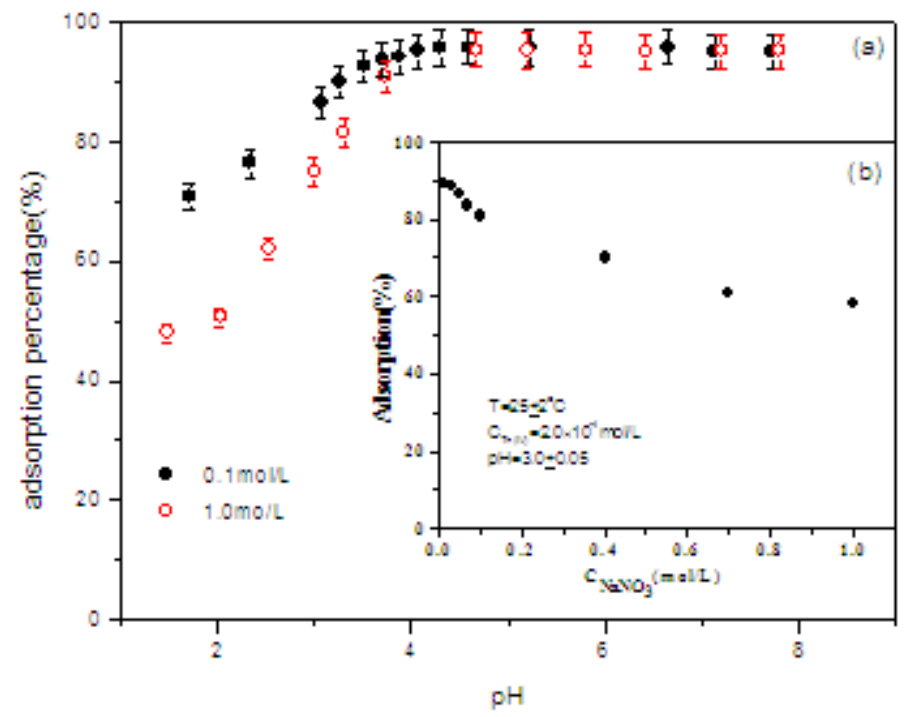

Fig 8. (a) Effect of pH on the adsorption of Th(IV) on natural illite.

(b) Effect of ionic strength on the adsorption of Th(IV) on natural illite

$$
T=25 \pm 2^{\circ} \mathrm{C}, C_{T h(I V)}=2.0 \times 10^{-4} \mathrm{~mol} / \mathrm{L}, p H=3.0 \pm 0.03, m / V=5 \mathrm{~g} / \mathrm{L}, t=20 \mathrm{~h}
$$

From Fig.8(b), sorption of Th(IV) on natural illite is affected by the concentration of $\mathrm{NaNO}_{3}$ strongly. This result is in conformity with the values of natural illite $\mathrm{H}_{s}$. The sorption of $\mathrm{Th}(\mathrm{IV})$ decreases with increasing $\mathrm{NaNO}_{3}$ concentration, which suggests that there is the strong competition between $\mathrm{Na}^{+}$and $\mathrm{Th}(\mathrm{IV})$ at the natural illite surface. It is well known that outer-sphere complexes and ion exchange can be can be affected by ionic strength, while inner-sphere complexes cannot be influenced by ionic 
strength and be affected by $\mathrm{pH}(\mathrm{Pan}$ et $a L, 2011$; Baeyens and Bradbury, 1997). Therefore, the results manifested ion exchange and outer-sphere complexes contribute to Th(IV) sorption on natural illite at low $\mathrm{pH}$ value. At high $\mathrm{pH}$ value, inner-sphere complexes and/or precipitation may dominate Th(IV) sorption on natural illite.

In general, surface complexation is influenced by $\mathrm{pH}$ values obviously, whereas ion exchange is influenced by ionic strength (Baeyens and Bradbury, 1997). The sorption mechanism of Th(IV) on natural illite is outer-sphere complexation or ion exchange (Yu et aL, 2007; Esmadi and Simm,1995) .

\subsection{Influence of Foreign Ions}

To investigate the influence of background electrolyte foreign cations, sorption of $\mathrm{Th}(\mathrm{IV})$ on natural illite were investigated in $0.1 \mathrm{M} \mathrm{NaNO}, \mathrm{KNO}_{3}$ and $\mathrm{Mg}\left(\mathrm{NO}_{3}\right)_{2}$ solutions, respectively. Fig.9(a) indicates that the negative influence on the sorption of $\mathrm{Th}(\mathrm{IV})$ from strong to weak is $\mathrm{Mg}\left(\mathrm{NO}_{3}\right)_{2}>\mathrm{KNO}_{3}>\mathrm{NaNO}_{3}$ under the same $\mathrm{pH}$ values, and the influence is more obvious on the sorption on natural illite, which indicating that cations can alter the surface properties of natural illite and thus can affect the sorption of Th(IV) on natural illite. The sorption of Th(IV) is affected by $\mathrm{K}^{+}$ since the sorption capability of $\mathrm{K}^{+}$is stronger than $\mathrm{Na}^{+}$. The hydrated radii of $\mathrm{K}^{+}$is greater than of $\mathrm{Na}^{+}$, hence the hydrated $\mathrm{K}^{+}$is easier to interact with the surface functional groups of natural illite. This results is similar to Th(IV) sorption on Na-bentonite(Pan et aL, 2011). Fig.9(a) also shows the effect of divalent cation $\left(\mathrm{Mg}^{2+}\right)$ on the sorption of Th(IV) on illite is stronger than $\mathrm{Na}^{+}$and $\mathrm{K}^{+}$. The sorption of cation was decreasing with the increasing valence of competitive cation, because the increasing cation valence made the potential in the plane of sorption less negative at $\mathrm{pH}<\mathrm{pH}_{\mathrm{PZC}}\left(\mathrm{H}_{\text {arter }}\right.$ and Naidu, 2001). The higher valent ions are much more easily and strongly adsorbed by natural illite, and the divalent cations would occupy twice sites more competitively by forming $(\equiv \mathrm{SO})_{2}-\mathrm{Mg}$. This conclusion is similar to Th(IV) adsorbed on Na-bentonite(Pan et aL, 2011). Therefore, the ionic valence plays a more important role in the sorption process than ionic radius. In short, At $\mathrm{pH}<6$, the sorption of Th(IV) on natural illite can be attributed to the exchange of Th(IV) with alkali metal cations or alkaline earth cations. One can also see that the sorption of Th(IV) on illite at $\mathrm{pH}>6$ is not affected by competing cations, which may be due to the formation of surface precipitates at high $\mathrm{pH}$ values(Yu et aL, 2015).
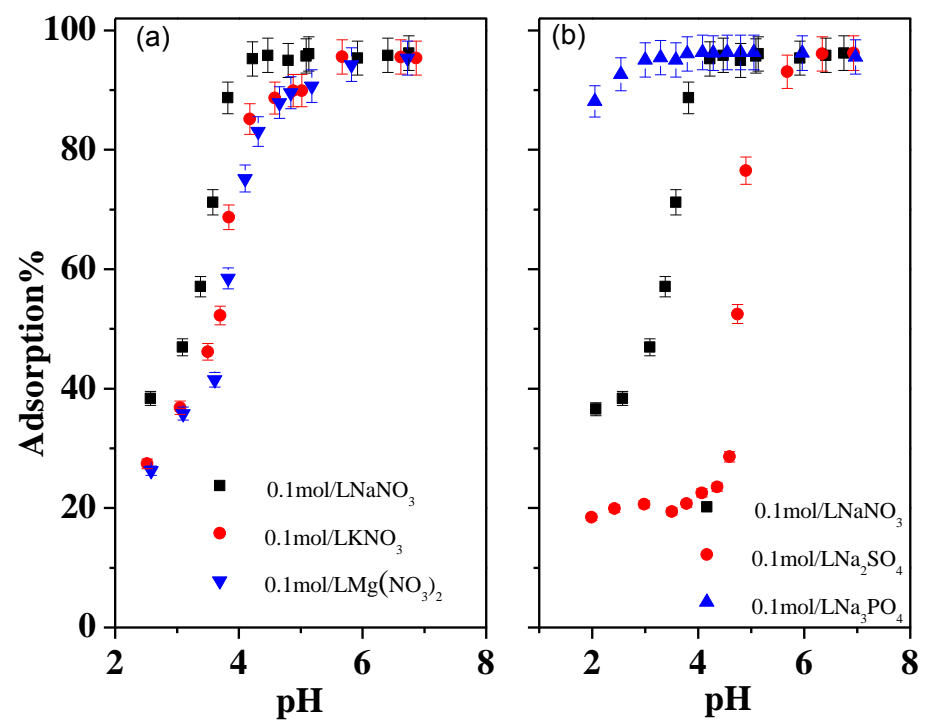

Fig.9 Effect of background electrolyte the adsorption of Th(IV) on natural illite,

(a) foreign cations (b) foreign anions. $T=25 \pm 2^{\circ} \mathrm{C}, C_{T h(I V)}=2.0 \times 10^{-4} \mathrm{~mol} / \mathrm{L}, m / V=3 \mathrm{~g} / \mathrm{L}, t=20 \mathrm{~h}$

To investigate the influence of background electrolyte foreign anions, sorption of Th(IV) on natural illite were investigated in $0.1 \mathrm{M} \mathrm{NaNO} 3, \mathrm{Na}_{2} \mathrm{SO}_{4}$ and $\mathrm{Na}_{3} \mathrm{PO}_{4}$ solutions, respectively. The influences of anions on Th(IV) sorption are plotted in Fig.9(b). The sorption of Th(IV) is obviously enhanced in the presence of $\mathrm{PO}_{4}{ }^{3-}$, while inhibited in the presence of $\mathrm{SO}_{4}{ }^{2-}$. This can be interpreted by the fact that, phosphate ions are more easily to be sorbed to natural illite surface than sulfate ions. In the presence 
of $\mathrm{PO}_{4}{ }^{3-}$, the ternary complexes of SO-Th- $\mathrm{PO}_{4}$ and/or SO-PO ${ }_{4}-\mathrm{Th}$ cause more Th(IV) ions to be sorbed(Pan et $a L, 2011)$. Sulfate has less affinity to surface of clay and oxide comparing with phosphate (Weijden et $a L, 1997$ ). Therefore, residual sulfate ions in aqueous favorably form soluble binary complexes reducing Th(IV) sorption on natural illite.

In general, the effect of cations on sorption of Th(IV) may be attributed to competitive sorption, while anions attributed to the strong complex abilities with Th(IV) (Xu et aL, 2007; Chen and Wang, 2007).

\subsection{Sorption Isotherm and Thermodynamic Data}

Sorption isotherm experiments at different temperatures are performed and the results are shown in Fig.10. It is found that the sorption amount of $\mathrm{Th}(\mathrm{IV})$ by natural illite increased with increasing temperature, indicating that high temperatures favored Th(IV) sorption.

In order to obtain a better understanding of the Th(IV) sorption mechanism, the Langmuir, Freundlich and $\mathrm{D}-\mathrm{R}$ sorption isotherms of $\mathrm{Th}(\mathrm{IV})$ at the three different temperatures are used to fit the experimental data, and the results are shown in Table 4, respectively. The relative parameters and the correlation coefficients calculated from Eqs.(10)-(14) are listed as follows (Chen et aL, 2007):

$$
\text { Langmuir: } \quad \frac{C_{e}}{q_{e}}=\frac{1}{K_{L} q_{\max }}+\frac{C_{e}}{q_{\max }}
$$

Freundlich:

$$
\begin{gathered}
\lg q_{e}=\lg K_{F}+n \lg C_{e} \\
\lg q_{e}=\lg q_{\max }-\beta \varepsilon^{2} \\
\varepsilon=-R \operatorname{Tlg}\left(1+1 / C_{e}\right) \\
E=1 / \sqrt{2 \beta}
\end{gathered}
$$

\begin{tabular}{|c|c|c|c|c|}
\hline \multirow{2}{*}{ Model } & \multirow{2}{*}{ Parameters } & \multicolumn{2}{|c|}{$\mathrm{T}(\mathrm{K})$} & \\
\hline & & 298.15 & 338.15 & \\
\hline \multirow{4}{*}{ Langmuir } & $q_{\text {max }}(\mathrm{mmol} / \mathrm{g})$ & 0.0649 & 0.0731 & 0.1065 \\
\hline & $\mathrm{K}_{\mathrm{L}}(\mathrm{L} / \mathrm{mol})$ & 137.29 & 129.49 & 91.84 \\
\hline & $\mathrm{R}^{2}$ & 0.9991 & 0.9975 & 0.9934 \\
\hline & RMSE & 0.0008 & 0.0015 & 0.0043 \\
\hline \multirow{4}{*}{ Freundlich } & $\mathrm{K}_{\mathrm{F}}\left(\mathrm{mol}^{1-\mathrm{n}} \mathrm{L}^{\mathrm{n}} / \mathrm{g}\right)$ & $4.19 \times 10^{-4}$ & $6.64 \times 10^{-4}$ & $7.04 \times 10^{-3}$ \\
\hline & $\mathrm{n}$ & 0.18 & 0.21 & 0.38 \\
\hline & $\mathrm{R}^{2}$ & 0.9482 & 0.9591 & 0.9721 \\
\hline & RMSE & 0.0358 & 0.0318 & 0.0917 \\
\hline \multirow{4}{*}{$\mathrm{D}-\mathrm{R}$} & $\mathrm{q}_{\max }(\mathrm{mmol} / \mathrm{g})$ & 0.1261 & 0.1593 & 0.4825 \\
\hline & $\mathrm{E}(\mathrm{kJ} / \mathrm{mol})$ & 14.35 & 14.18 & 13.09 \\
\hline & $\mathrm{R}^{2}$ & 0.9682 & 0.9763 & 0.9791 \\
\hline & RMSE & 0.0298 & 0.0276 & 0.0253 \\
\hline
\end{tabular}

Table 4. The parameters of Langmuir, Freundlich and D-R models

where $\mathrm{q}_{\max }$, the maximum sorption capacity, is the amount of $\mathrm{Th}(\mathrm{IV})$ at complete monolayer coverage $(\mathrm{mol} / \mathrm{g}), K_{L}$ is the constant that relates to the heat of sorption $(\mathrm{L} / \mathrm{mol}) . K_{F}$ and $n$ are represents the sorption capacity when Th(IV) equilibrium concentration equals to 1 , and $n$ represents the degree of dependence of sorption with equilibrium concentration. $\varepsilon$ is the Polanyi potential, $R$ is ideal gas constant, and $T$ is the absolute temperature $(\mathrm{K})$. The value of $\beta$ is the activity coefficient related to mean sorption energy $\left(\mathrm{mol}^{2} / \mathrm{kJ}^{2}\right)$. It is related with the adsorption mean free energy, $\mathrm{E}(\mathrm{kJ} / \mathrm{mol})$, defined as the free energy change required to transfer one mole of ions from infinity in solution to the solid surfaces. The linear plots of Langmuir Freundlich and D-R equation representing Th(IV) sorption are shown in Fig.10. 

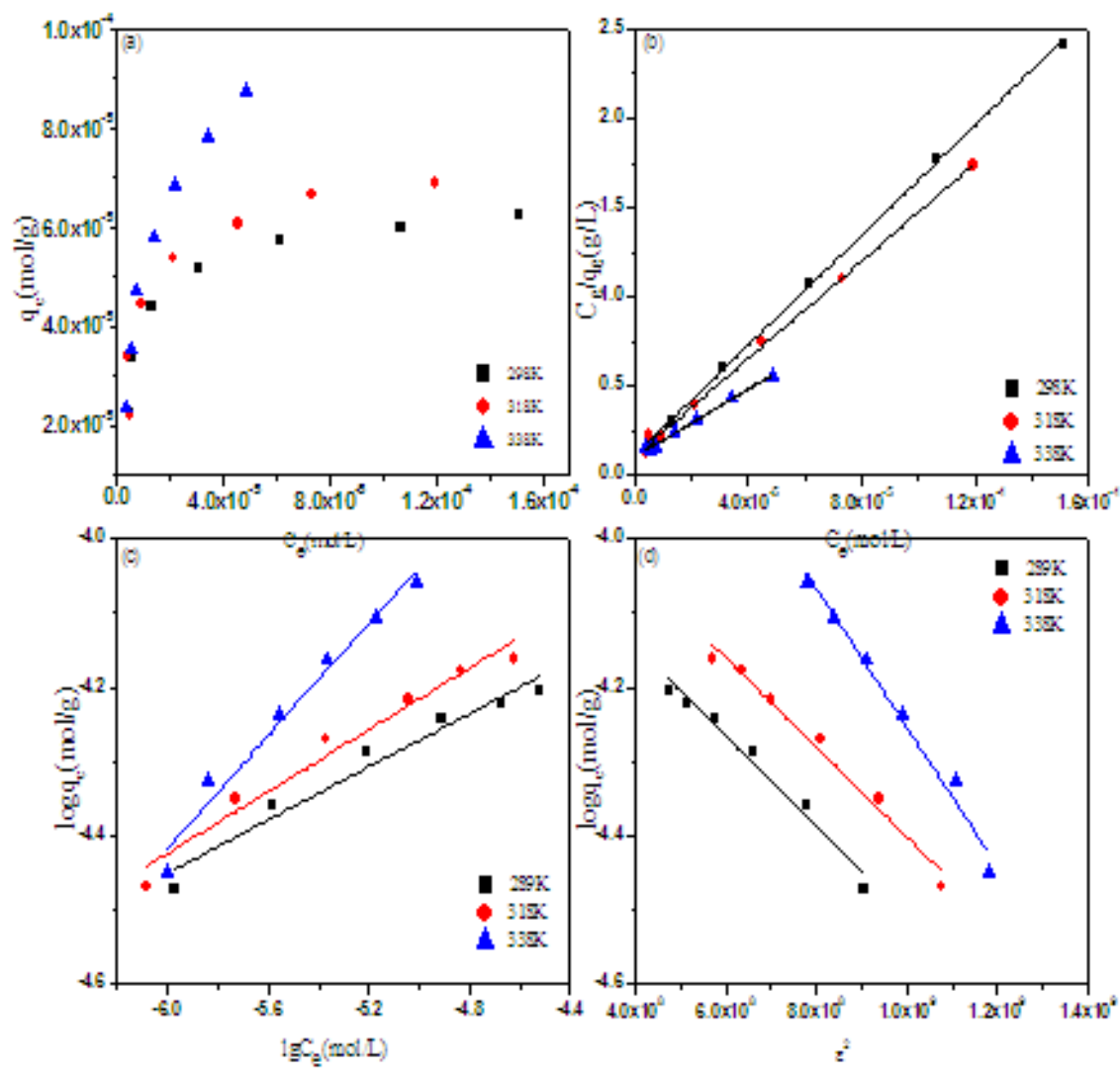

Fig 10. The effect of temperature on the adsorption adsorption isotherm of Th(IV) on natural illite. $p H=3.5 \pm 0.03, m / V=5 \mathrm{~g} / \mathrm{L}, t=20 \mathrm{~h}, I=0.01 \mathrm{M} \mathrm{NaNO}_{3}$.

(b)Langmuir, (c)Freundlich, (d) D-R

The higher correlation coefficients and a smaller RMSE indicate that the sorption can be fitted by the Langmuir model better than by the Freundlich and D-R models. From Langmuir model, the maximum sorption $\left(\mathrm{q}_{\max }\right)$ increases with increasing temperature, which suggests that sorption of $\mathrm{Th}(\mathrm{IV})$ on illite increases with increasing temperature. Similar results are also found in D-R model. The maximum sorption of Th(IV) calculated from Langmuir model are about $10^{-5} \sim 10^{-4} \mathrm{~mol} / \mathrm{g}$, and the results calculated by the two models are not an exact match maybe attributed to the different assumptions considered in the formulation of the isotherms. Adsorption mean free energy (E) shows that $\mathrm{Th}(\mathrm{IV})$ adsorption on the natural illite is chemical adsorption.

The thermodynamic parameters for Th(IV) sorption on natural illite can be calculated from the temperature dependent sorption isotherms. The relevant data $\left(\Delta G^{0}, \Delta S^{0}, \Delta H^{0}\right)$ are listed in Table 5. It is evident that the values of $\Delta \mathrm{H}^{0}$ are positive, i.e. endothermic. The Gibbs free energy change $\left(\Delta G^{0}\right)$ is negative as expected for a spontaneous process under the conditions applied. The decrease in $\Delta G^{0}$ with the increasing temperature indicates more efficient adsorption at higher temperature. The positive values of entropy change $\left(\Delta S^{0}\right)$ reflect the affinity of illite toward Th(IV) ions in aqueous solutions and may suggest some structure changes in the adsorbents(Fan et $a L, 2012$; Fan et $a L$, 2009).

Table 5. The thermodynamic data of Th(IV) adsorption on natural illite

\begin{tabular}{|c|c|c|c|}
\hline $\mathrm{T}(\mathrm{K})$ & $\Delta \mathrm{G}^{0}(\mathrm{~kJ} / \mathrm{mol})$ & $\Delta \mathrm{H}^{0}(\mathrm{~kJ} / \mathrm{mol})$ & $\Delta \mathrm{S}^{0}(\mathrm{~J} / \mathrm{mol} \cdot \mathrm{K})$ \\
\hline 298.15 & -20.74 & 11.24 & 107.25 \\
\hline 318.15 & -22.64 & 11.48 & \\
\hline 338.15 & -25.03 & 11.24 & \\
\hline
\end{tabular}

\subsection{Adsorption and desorption of Th(IV) on natural illite}

The desorption behavior is conducive to understand the interaction mechanism between thorium and natural illite. Sorption and desorption isotherms of Th(IV) on natural illite at $25 \pm 2^{\circ} \mathrm{C}$ and $45 \pm 2^{\circ} \mathrm{C}$ are shown in Fig.11(a)(b), respectively. The reversible process is complete desorption without any 
interventions, while irreversible process indicates that complete desorption cannot occur without intervention(Xu et aL, 2016). For the sorption of Th(IV) on natural illite, the isotherm of desorption at different temperatures obviously overlaps that of sorption. The sorption process on natural illite was reversible process with no desorption hysteresis. The adsorbed Th(IV) on natural illite can be easily desorption. Moreover, from Fig.11a and b, high temperatures favor Th(IV) sorption because Th(IV) sorption increased with increasing temperatures, and indicating that the sorption process was endothermic.

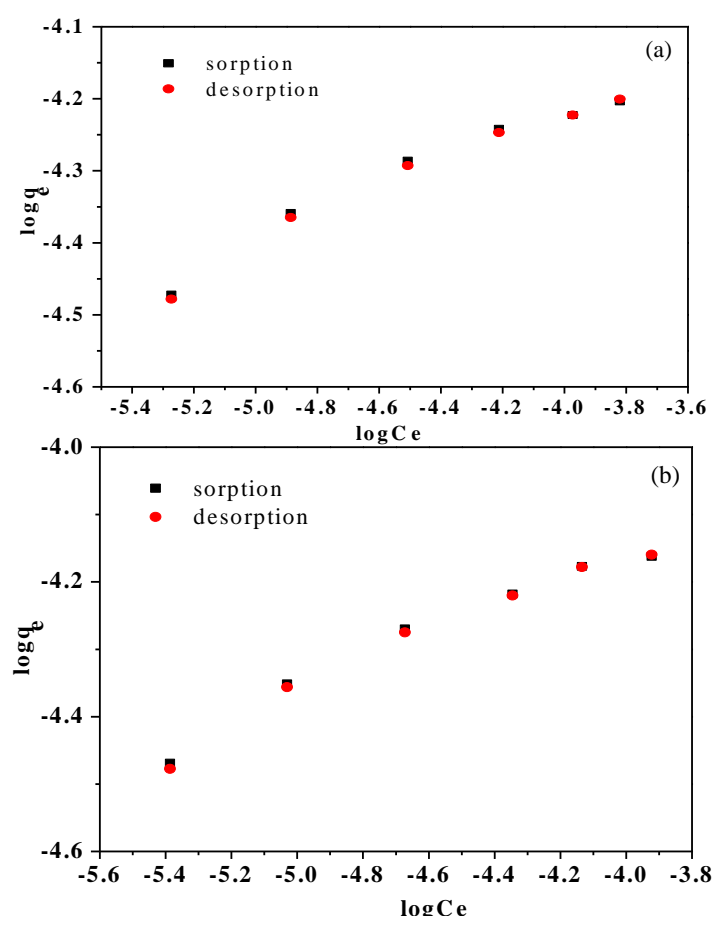

Fig 11. Adsorption and desorption isotherms of Th(IV) on natural illite.(a) $\mathrm{T}=25 \pm 2^{\circ} \mathrm{C}$,

(b) $45 \pm 2^{\circ} \mathrm{C}, \mathrm{pH}=3.5 \pm 0.03, \mathrm{~m} / \mathrm{V}=5 \mathrm{~g} / \mathrm{L}, \mathrm{t}=24 \mathrm{~h}, \mathrm{I}=0.01 \mathrm{~mol} / \mathrm{L} \mathrm{NaNO}_{3}$.

\subsection{X-ray photoelectron spectroscopy analysis}

The XPS spectroscopy technique is used to determine the interaction mechanism between Th(IV) and natural illite. Fig.12 showed the total scans of XPS spectrum of illite before and after the adsorption experiments. The figure revealed that oxygen was the predominant element observed on the surface of illite. After adsorption, the peaks of Th are observed, indicating that Th(IV) was adsorbed on natural illite and the intensity of Th(IV) peak was higher in $\mathrm{pH} 5.5$, which illustrates that the adsorption capacity of Th(IV) was larger than that of higher $\mathrm{pH}$.

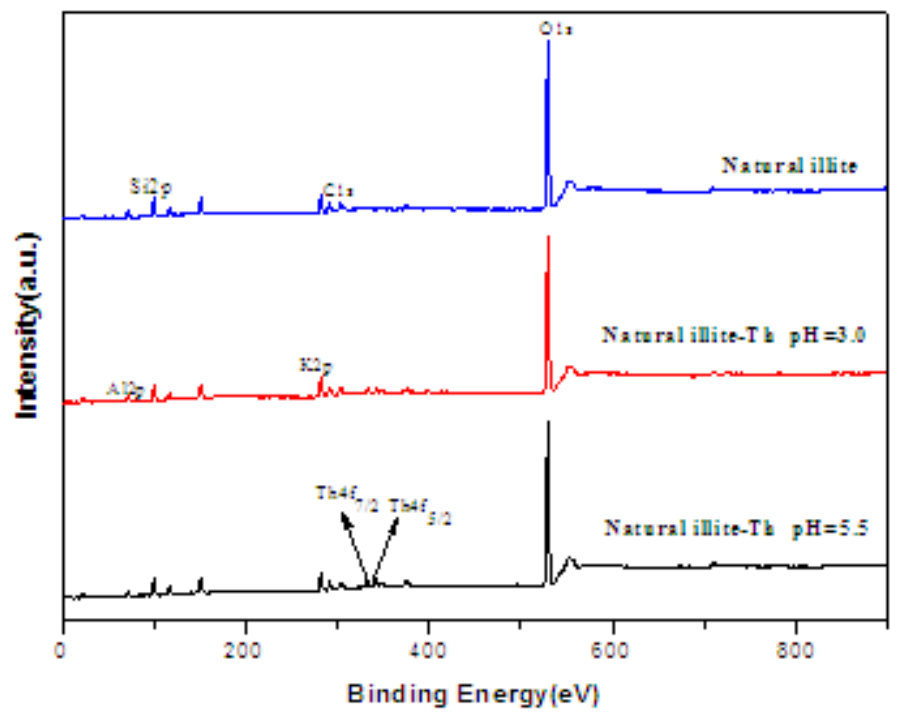

Fig 12. The total scans of XPS spectrum of natural illite before and after Th(IV) sorption.

$$
\mathrm{T}=25 \pm 2^{\circ} \mathrm{C}, \mathrm{C}_{\mathrm{Th}(\mathrm{IV})}=2.0 \times 10^{-4} \mathrm{~mol} / \mathrm{L}, \mathrm{m} / \mathrm{V}=5 \mathrm{~g} / \mathrm{L}, \mathrm{t}=20 \mathrm{~h}
$$


The high resolution of Th peaks is provided in Fig.13. Table 6 lists a summary of peak position of the XPS spectra. Th4f spectra before and after sorption could be characterized with two doublet-peaks Th $4 \mathrm{f}_{7 / 2}$ and $\mathrm{Th} 4 \mathrm{f}_{5 / 2}$ for Th $4 \mathrm{f}$. As showed in Fig.13 (e), the peaks of binding energy for $\mathrm{Th}\left(\mathrm{NO}_{3}\right)_{4}$ are centered at $334.0 \mathrm{eV}$ for Th $4 \mathrm{f}_{7 / 2}$ and $342.3 \mathrm{eV}$ for $\mathrm{Th} 4 \mathrm{f}_{5 / 2}$, respectively. The peaks of binding energy for $\mathrm{Th}(\mathrm{OH})_{4}$ are higher energy ( $334.5 \mathrm{eV}$ for $\mathrm{Th} 4 \mathrm{f}_{7 / 2}$ and $343.8 \mathrm{eV}$ for $\mathrm{Th}_{4 \mathrm{f}_{5 / 2}}$ ) in Fig.13(d). As can be seen in Fig.13 (b) and (c), The adsorbed Th(IV) of the binding energies of the Th4f are shifted to lower values (in Table 6) for Th($\left(\mathrm{NO}_{3}\right)_{4}$. The main peaks position of Th4f in Fig. 13 (b) (c) is different with (d) (e), indicating that Th(IV) adsorbed on natural illite is not the existing forms of $\mathrm{Th}\left(\mathrm{NO}_{3}\right)_{4}$ or $\mathrm{Th}(\mathrm{OH})_{4}$. It shows $\mathrm{Th}(\mathrm{IV})$ adsorbed on natural illite is attributed to cation exchange or surface complexation, and Th strongly adsorbed on the natural illite inhibits the $\mathrm{Th}(\mathrm{OH})_{4}$ precipitate generated on the natural illite. At the same time, the binding energy of $T h 4 f_{5 / 2}$ and $T h 4 f_{7 / 2}$ sorption of $\mathrm{Th}(\mathrm{IV})$ is lower in $\mathrm{pH}$ at 5.5 than $\mathrm{pH} 3$, which indicates the existing forms of $\mathrm{Th}(\mathrm{IV})$ sorbed on illite are different under the two different experimental conditions.

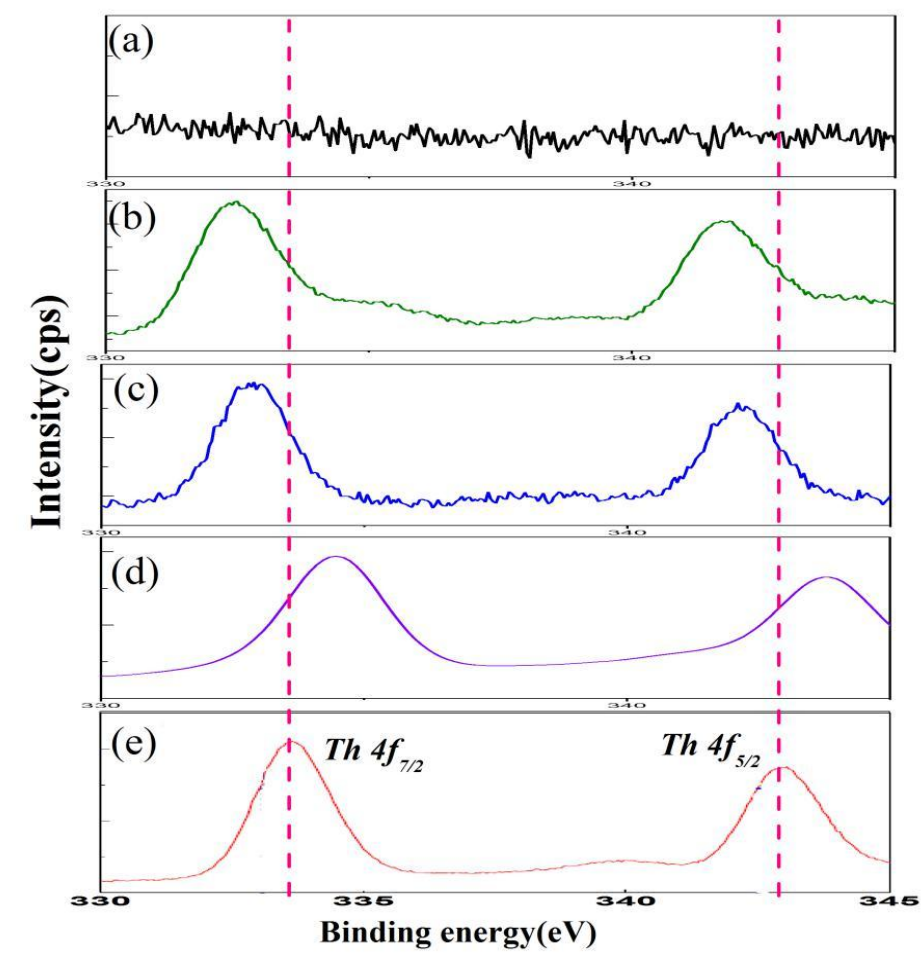

Fig 13. The high-resolution Th $4 \mathrm{f}$ spectra and XPS spectrum of the natural illite

(a) Natural illite; (b) $\mathrm{pH}=5.5$; (c) $\mathrm{pH}=3.0$; (d) $\mathrm{Th}(\mathrm{OH})_{4}$ (s); (e) $\mathrm{Th}\left(\mathrm{NO}_{3}\right)_{4}$; $T=25 \pm 2^{\circ} \mathrm{C}, C_{T h(I V)}=2.0 \times 10^{-4} \mathrm{~mol} / \mathrm{L}, m / V=5 \mathrm{~g} / \mathrm{L}, t=20 \mathrm{~h}$.

Table 6. Th4f of binding energy

\begin{tabular}{|l|c|c|}
\hline & $\mathrm{Th}_{4} \mathrm{f}_{7 / 2}(\mathrm{eV})$ & $\mathrm{Th}_{\mathrm{f}}(\mathrm{eV})$ \\
\hline $\mathrm{pH} 5.5$ & 332.4 & 341.1 \\
\hline $\mathrm{pH} \mathrm{3.0}$ & 332.9 & 341.7 \\
\hline $\mathrm{Th}(\mathrm{OH})_{4}$ & 334.5 & 343.8 \\
\hline $\mathrm{Th}\left(\mathrm{NO}_{3}\right)_{4}$ & 334.0 & 342.3 \\
\hline
\end{tabular}

\section{Conclusions}

The results of Th(IV) sorption on natural illite at various experimental conditions, the conclusions can be drawn as follows: The sorption of $\mathrm{Th}(\mathrm{IV})$ can be described by a pseudo-second-order rate equation well. The sorption of Th(IV) is influenced by temperature obviously. Sorption of $\mathrm{Th}(\mathrm{IV})$ on natural illite is a spontaneous endothermic process, and can be described by Langmuir model. The sorption of $\mathrm{Th}(\mathrm{IV})$ on natural illite is also influenced by solid-to-liquid ratio and foreign ions obviously. Sorption of Th(IV) on natural illite is mainly dominated by outer-sphere complexation on the hydroxyl groups on the edge of natural illite sheet and ion exchange on the permanent negative charge of natural illite. Compared with pure illite, the sorption of $\mathrm{Th}(\mathrm{IV})$ on natural illite is much better under the same conditions. 


\section{ACKNOWLEDGEMENTS}

National Natural Science Foundation of China $(21101083,21641003)$ is gratefully acknowledged.

\section{REFERENCES}

Asci, Y., Nurbas, M. and Acikel, Y.S., 2007. Sorption of Cd(II) onto kaolin as a soil component and desorption of Cd(II) from kaolin using rhamnolipid biosurfactant. J Hazard Mater. 139(1), 50-56.

Boyd, S.A., Lee, J.F., Mortland, M.M., 1988. Attenuating organic contaminant mobility by soil modification. Nature. 333, 345-347.

Baeyens, B., Bradbury, M. H., 1997. A mechanistic description of $\mathrm{Ni}$ and $\mathrm{Zn}$ sorption on Namontmorillonite. Part 1: Titration and sorption measurements. J. Contam. Hydrol. 27, 199-222.

Bradbury M. H. and Baeyens B., 2009. Sorption modelling on illite, Part II: Actinide sorption and linear free energy relationships. Geochim. Cosmochim. Acta. 73, 1004-1013.

Chang, P.P., Wang, X.K., Yu, S.M., Wu, W.S., 2007. Sorption of Ni(II) on Na-rectorite from aqueous solution: Effect of pH, ionic strength and temperature. Colloids Surface A. 302, 75-81.

Chen, C.L., Li, X.L., Zhao, D.L., Tan, X.L., Wang, X.K., 2007. Adsorption kinetic, thermodynamic and desorption studies of Th(IV) on oxidized multi-wall carbon nanotubes. Colloids and surf. A. 302, 449-454.

Chen, C.L., Li, X.L., Wang, X.K., 2007. Application of oxidized multi-wall carbon nanotubes for Th(IV) adsorption. Radiochim. Acta. 95, 261-266.

Chen, C.L., Wang, X.K., 2007.Sorption of Th(IV) to silica as a function of pH, humic/fulvic acid, ionic strength, electrolyte type. Appl. Radiat. Isot. 65, 155-163.

C.L. Chen, X.K. Wang, 2007. Influence of $\mathrm{pH}$, soil humic/fulvic acid, ionic strength and foreign ions on sorption of thorium(IV) onto $\gamma-\mathrm{Al}_{2} \mathrm{O}_{3}$, Appl. Geochem. 22,436-445.

Choppin, G.R., 1999. Utility of oxidation state analogs in the study of plutonium behavior. Radiochim. Acta 85, 89-96.

Echeverría, J. C., Zarranz, I., Estella, J., Garrido, J. J., 2005. Simultaneous effect of pH, temperature, ionic strength, and initial concentration on the retention of lead on illite. Appl. Clay Sci. 30, 103115.

Elzinga, E.J., Sparks, D.L., 2001. Reaction conditions effects on nickel sorption mechanisms in illite water suspensions. Soil Sci. Soc. Am. J. 65, 95-101.

Esmadi, F. and Simm, J., 1995. Sorption of cobalt(II) by amorphous ferrichydroxide[J]. Colloids Surf. A. 104: 265-270.

Q. H. Fan, W. S. Wu, X. P. Song, J. Z. Xu, J. Hu, Z. W. Niu, 2008. Effect of humic acid, fulvic acid, $\mathrm{pH}$ and temperature on the sorption-desorption of Th(IV) on attapulgite. Radiochim. Acta. 96, 159-165.

Fan, Q. H., Tan, X. L., Li, J. X., Wang, X. K., Wu, W. S., Montavon, G., 2009. Sorption of Eu(III) on attapulgite studied by batch, XPS, and EXAFS techniques. J. Environ. Sci. Technol. 43, 57765782.

Fan, Q. H., Xu, J. Z., Niu, Z. W., Li, P., Wu, W.S., 2012. Investigation of Cs(I) uptake on Beishan soil combined batch and EDS techniques. J. Appl. Isot. 70, 13-19.

Giustetto, R., Xamena, F.X.L., Ricchiardi, G., Bordiga, S., Damin, A., Gobetto, R., Chierotti, M.R., 2005. Maya Blue: A computational and Spectroscope Study. J. Phys. Chem. B. 109, 1936019368.

Ho Y.S., 2006. Second-order kinetic model for the sorption of cadmium onto tree fern: A comparison of linear and non-linear methods, Wat. Res. 40,119-125.

Ho Y.S., Makay G., 2000. The Kinetics of Sorption of Divalent Metal Ions onto Sphagnum Moss Peat. Wat Res. 34(3), 735-742.

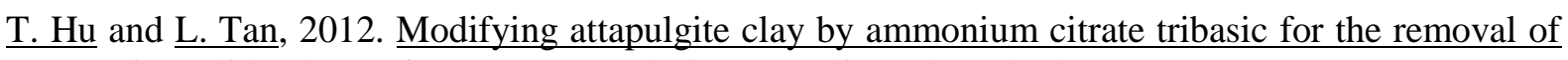
radionuclide Th(IV) from aqueous solution. J Radioanal Nucl Chem. 292(2), 819-827.

R. D. Harter, R. Naidu, 2001. An assessment of environmental and solution parameter impact on trace-metal sorption by soil. Soil Sci. Soc. Am. J. 65, 597-612.

Jakobsson, A.M., 1999. Measurement and modeling of Th sorption onto $\mathrm{TiO}_{2}$. J. Colloid Interface Sci. 220, 367-373. 
Jan Środoń, 2005. Illite group clay minerals, Encycclopedia of earth science, pp597-601.

A. Kitamura, A. Kirishima,2015. Recent activities in the field of nuclear waste management. J. Nucl. Sci. Technol. 52, 448-450.

Liu, W. X., Sun, Z. X., Forsling, W., Tang, H. X., 1999. A comparative study of Acid-base characteristics of natural illites from different origins. J. Colloid Interf. Sci. 219, 48-61.

D. Pan, Q. Fan, P. Li, S. Liu, W. Wu., 2011. Sorption of Th(IV) on Na-bentonite: Effects of pH, ionic strength, humic substances and temperature. J. Chem. Eng. 172, 898-905.

Potgieter, J. H., Potgieter-Vermaak, S. S., Kalibantonga, P.D., 2006. Heavy metals removal from solution by palygorskite clay. Miner. Eng. 19, 463-470.

Reiller, P., Casanova, F., Moulin, V., 2005. Influence of addition order and contact time on thorium(IV) retention by hematite in the presence of humic acids. Environ. Sci. Technol. 39, $1641-1648$.

Rieder, M., Cavazzini, G., D'yakonov, Y. Viktor, A.Frank Kamenetskii, Glauco Gottardi, Stephen Guggenheim, Pavel V. Koval', Georg Müller, Ana M. R. Neiva, Edward W. Radoslovich, Jean Louis Robert, Francesco P. Sassi, Hiroshi Takeda, Zdeněk Weiss, David, R. Wones, 1999. Nomenclature of the micas, Mineralogical Magazine. 63(2), 267-279.

Tan, X.L., Wang, X.K., Chen, C.L., Sun, A.H., 2007. Effect of soil humic and fulvic acids, pH and ionic strength on $\mathrm{Th}(\mathrm{IV})$ sorption to $\mathrm{TiO}_{2}$ nanoparticles. Appl. Radiat. Isot. 65, 375-381.

Turan, N.G., Elevli, S., Mesci, B., 2011. Adsorption of copper and zinc ions on illite: determination of the optional conditions by statistical design of experiment. Appl. Clay Sci.52, 392-399.

Wagner, C. D., Riggs, W. M., Davis, L. E., Moulder, J. F., Muilenberg, G. E., Eds., Perkin-Elmer Corp., Handbook of X-ray Photoelectron Spectroscopy. Physical Electronics Division: Eden Prairie, MN, 1979.

Wang, X.K., Chen, C.L., Zhou, X., Tan, X.L., Hu, W.P., 2005a. Diffusion and sorption of U(VI) incompacted bentonite studied by a capillary method. Radiochim. Acta. 93, 273-278.

Wang, X.K., Tan, X.L., Chen, C.L., Chen, L., 2005b. The concentration and pH dependent diffusion of ${ }^{137} \mathrm{Cs}$ incompacted bentonite by using capillary method. J. Nucl. Mater. 345, 184-191.

Wang, X.K., Chen, C.L., Hu, W.P., Ding, A.P., Xu, D., Zhou, X., 2005c. Sorption of ${ }^{243} \mathrm{Am}(\mathrm{III})$ to multiwall carbon nanotubes. Environ. Sci. Technol. 39, 2856-2860.

Weijden, R.D., Meima, J., Comans, R.N.J., 1997. Sorption and sorption reversibility of cadmium on calcite in the presence of phosphate and sulfate. J. Mar. Chem. 57, 2389-2396.

T. Wen, X.L. Wu, M.C. Liu, Z.H. Xing, X.K. Wang, A.W. Xu, 2014. Efficient capture of strontium aqueous solutions using graphene oxide-hydroxyapatite nanocomposites, Dalton Trans. 43,7464-7472.

Wu, W.S., Fan, Q.H., Xu, J.Z., Niu, Z.W., Lu, S.S., 2007. Sorption-desorption of Th(IV) on attapulgite: Effects of $\mathrm{pH}$, ionic strength and temperature, Appl. Radiat. Isot. 65, 1108-1114.

Xu, D., Chen, C.L., Tan, X.L., Wang, X.K., 2007. Sorption of Th(IV) on Na-rectorite: effect of HA, ionic strength, foreign ions and temperature. Appl. Geochem. 22, 2892-2906.

Xu, D., Shao, D.C., Chen, L., Ren, A.P., Wang, X.K., 2006. Effect of pH and fulvic acid on sorption and complexation of cobalt onto bare and FA bound MX-80 bentonite. Radiochim. Acta. 94, 97102.

Xu, H., LI, G., Li, J., Chen, Ch.L., Ren, X.M., 2016. Interaction of Th(IV) with graphene oxides: batch experiments, XPS investigation, and modeling. Journal of Molecular Liquids.213,58-68.

Xu, S., Boyd, S.A., 1994. Cation exchange chemistry of hexadecyltrimethylammonium in a subsoil containing vermiculite. Soil Sci. Soc. Am. J. 58, 1382-1391.

Yari, S., Abbasizadeh, S., Mousavi, S.E., Moghaddam, M.S., Moghaddam, A.Z., 2015. Adsorption of $\mathrm{Pb}$ (II) and $\mathrm{Cu}$ (II) ions from aqueous solution by an electrospun $\mathrm{CeO}_{2}$ nanofiber adsorbent functionalized with mercapto groups. Process Saf. Environ. Protect. 94, 159-171.

Yu, S.M., Chen, C.L., Chang, P.P., Wang, T.T., Lu, S.S., Wang, X.K., 2007. Adsorption of Th(IV) onto Al-pillared rectorite: Effect of $\mathrm{pH}$, ionic strength, temperature, soil humic acid and fulvic acid. Applied Clay Sci. 38, 219-216. 
Yu, S.J., Mei, H.Y., Chen, X., Tan, X.L., Ahmad, B., Alsaedi, A., Hayat, T., Wang, X.K., 2015. Impact of environmental conditions on the sorption behavior of radionuclide $90 \mathrm{Sr}$ (II) on Namontmorillonite. J. Mol. Liq. 203, 39-46.

Zhang, H. X. , Niu, Zh. W. , Liu, Zh. , Wen, Zh. D. , Li, W. P. , Wang, X.Y. , Wu, W. S., 2015. Equilibrium, kinetic and thermodynamic studies of adsorption of Th(IV) from aqueous solution onto kaolin. J Radioanal Nucl Chem. 303, 87-97.

Zhang, H. X., Wang X.Y., Liang H. H., Tan T. S., Wu W. S., 2016. Adsorption behavior of Th(IV)

onto illite: effect of contact time, $\mathrm{pH}$ value, ionic strength, humic acid and temperature. Applied clay Science, 127-128, 35-43.

Zhao, D., Zhou, J., Liu, N., 2007. Surface characteristics and photo activity of silver-modified palygorskite clays coated with nanosized titanium dioxide particles. Mater. Charact. 58, 249-255. 